\title{
Voltage Quality Improvement using Statcom in Grid Connected Wind Turbines
}

\author{
Le Viet Tien*1, Vu Anh Tuan ${ }^{2}$ \\ ${ }^{* 1}$ Department of Electronic Engineering, Hanoi University \\ of Industry (HaUI), Hanoi, Vietnam \\ ${ }^{2}$ Department of Electrical Engineering, Hanoi University of \\ Industry (HaUI), Hanoi, Vietnam
}

\author{
Pham Ngoc Hung ${ }^{3}$ \\ ${ }^{3}$ Department of Electrical Engineering, \\ Electric Power University (EPU), Hanoi, \\ Vietnam
}

\begin{abstract}
Operation of wind turbines has an impact on the power quality at the connected electric network. The effects of the power quality measurements are the active power, reactive power, variation of voltage, flicker, harmonics, and electrical behavior of switching operations. The installation of wind turbine with the grid causes power quality problems are determined by studying this paper. The aim of this paper is to conduct a voltage stability analysis using an iterative power system simulation package, PSCAD/EMTDC simulator, to evaluate the impact of strategically placed wind turbine on distribution systems when subjected to a fault, and with that respect the critical voltage variations and collapse marginsare studied. This paper concludes with the discussion of wind turbine excellent options for system reactive power compensation and voltage stability
\end{abstract}

Keywords-Power quality, wind turbine, Statcom, PV curve, QV curve

\section{INTRODUCTION}

In recent years, rapid development in power electronics and control techniques has presented a new power electronic shunt compensation equipment with turn off switching capability. The device is called a Static Synchronous Compensator (Statcom). This device has a robust output and rapid response which can offer excellent contribution to the enhancement of power systems performance

The basis of Statcom technology is the use of electronic switches in the form of a power converter that creates a voltage source to synthesize the $\mathrm{V}_{\mathrm{c}}$ output voltage from a DC voltage source. Alternating voltage $\mathrm{V}_{\mathrm{c}}$ of the converter is connected to the electrical system via $X_{c}$ buffer reactance. By controlling the voltage Vc of Statcom, which is in phase with the system voltage Vs, but with a larger amplitude, the current and reactive power run from Statcom into the system, to raise the voltage.

Conversely, if the control voltage $\mathrm{V}_{\mathrm{c}}$ is lower than the system voltage $V_{s}$, then the current and power flows from the grid into Statcom, thus limiting overvoltage on the grid. Statcom's main advantage over traditional SVC is its ability to generate completely capacitive current at extremely low voltage, something that SVC cannot do. Another advantage is its compact size, good harmonics, little or no filtering, better dynamic response, better transitions, less noise, and a lower magnetic field. By appropriately controlling the output voltage of the Statcom set to be higher or lower than the secondary busbar voltage of the booster transformer, the compensation device can collect the capacitance or inductance from the system. The statcom is made up of triangular single phase converters, so it is possible to set each phase of the current in each phase separately so that it is suitable for general practical conditions during turbulence and reduced inverse order voltage or unbalance on $\mathrm{AC}$ system [1].

The Statcom is a shunt connected device that is capable of generating and/ or absorbing reactive power. In these the output can be varied to control the specific parameters of an electric power system. Because of fast switching characteristics its response time is fast as compared to SVC (Static VAR Compensator) [2]. Statcom acts as interlink between renewable resources and grid system and also for real power exchange between them. Statcom is an electronic device it has no inertia so it is more superior to the synchronous condenser. The Statcom has similar characteristics with the synchronous condenser. So it has better dynamics, a lower maintenance cost as well as investment cost. Statcom consist of three parts a controller, a step up coupling transformer and a voltage source converter as shown in fig. 1. For high voltage system the leakage inductance from transformer can act as coupling reactors. Coupling inductor filters out the current harmonic components that are generated by the pulsating output voltage of power converter mainly.

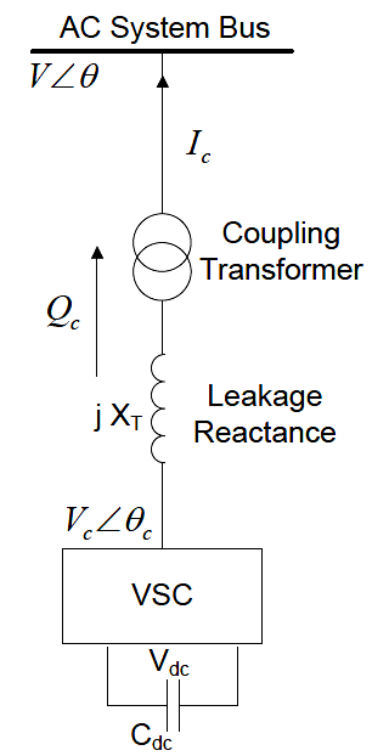

Figure 1. Basic model of Statcom [3]

Statcom acts as an inter-link between renewable energy resource and grid system. It also has the ability to exchange real power between the wind energy and load. When load 
requires reactive power Statcom takes active part in delivering the reactive power to the load. When load reactive power is more Statcom supplies the reactive power back to the grid. During light load there will be some losses in the system. Statcom consist of VSI that use advanced power switches for providing fast response and flexible voltage control. PWM when connected with converter will provide smooth current and low harmonics. A Statcom based control technology for improving the power quality can manages the power level associates with the wind turbines. The Statcom control scheme for grid connected wind energy generation for power quality improvement has following objectives.

- Reactive power support only from Statcom to wind Generator and Load.

- Unity power factor at the source side.

\section{STUDY OF POWER AND VOLTAGE} DISTURBANCES PRODUCED BY WIND POWER GENERATION

The stochastic behaviour of the wind gives rise to an irregular profile of the power generated from wind turbines and therefore constitute a potential source of deficient power quality and disturbances in the grid if the generators are connected to a weak system. Usually the highest wind potential exists in rural and coastal areas where the grids are weaker. For this reason, the amount of large scale wind power connection is limited by the grid characteristics. Two main phenomena are considered [4]:

Voltage variations result from wind gusts and slow changes in wind speed. The changes in power from variations of wind speed can be in the order of $60 \%$ in 3 minutes, depending on the location and the wind direction. The standards set a limit of amplitude of variation in function of how often these variations occur. The IEC 868 Standard allows a maximum value of $3 \%$ of voltage variation if they occur in 1 minute period or lower incidence frequency.

Flicker refers to the oscillations occurring at frequencies between 1 and $2 \mathrm{~Hz}$. This phenomena is associated to the tower shadow effect together with the wind gradient in wind turbines operation. For a single turbine, the amplitude of the power fluctuations can have a typical magnitude of $\pm 10 \%$ deviation from the average, but the mechanical resonance frequency of the tower can make these fluctuations as high as $\pm 20 \%$. For a wind power park with several turbines, the average power fluctuation is less than for a single turbine.

\section{USE OF STATCOM FOR IMPROVING SYSTEM PERFORMANCE}

When constant speed directly connected turbines are used, the power control is not possible, and consequently the voltage will be subjected to factors that disturb the power absorbed by the wind turbine. Voltage control by reactive power can avoid the necessity of using variable speed converters to eliminate voltage fluctuations. This can be a very effective way to improve the voltage quality when the grid $\mathrm{X} / \mathrm{R}$ ratio is high enough. If the $\mathrm{X} / \mathrm{R}$ ratio is low, then reactive power compensation becomes less effective.

\section{FACTS solutions}

FACTS technology allows greater flexibility for voltage and power flow control in power systems offering a number of unique features that makes them effective to handle power quality issues introduced by the connection of large wind farms. Two FACTS power electronic device solutions such as SVC (Static VAR Compensator) and STATCOM (Static Synchronous Compensator) are described as follows.

The STATCOM belongs to a family of power electronics controllers that base their operation on the Voltage Source Converter principle. The most basic configuration of the STATCOM consists of a two-level VSC with a dc energy storage device; a coupling transformer connected in shunt with the ac system, and associated control circuits. The dc energy storage device may be a battery, whose output voltage remains constant or it may be a capacitor, whose terminal voltage can be raised or lowered by means of suitable converter control.

\section{VOLTAGE STABILITY}

A system experiences a state of voltage instability when there is a progressive or uncontrollable drop in voltage magnitude after a disturbance, increase in load demand or change in operating condition. The main factor, which causes these unacceptable voltage profiles, is the inability of the distribution system to meet the demand for reactive power [4, 5].

Under normal operating conditions, the bus voltage magnitude (V) increases as $\mathrm{Q}$ injected at the same bus is increased. However,when V of any one of the system's buses decreases with the increase in $\mathrm{Q}$ for that same bus, the system is said to be unstable. Although the voltage instability is a localised problem, its impact on the system can be wide spread as it depends on the relationship between transmitted $\mathrm{P}$, injected $\mathrm{Q}$ and receiving end $\mathrm{V}$. These relationships play an important role in the stability analysis and can be displayed graphically.

\section{A. PV Curves}

When considering voltage stability, the relationship between transmitted $\mathrm{P}$ and receiving end $\mathrm{V}$ is of interest. The voltage stability analysis process involves the transfer of $\mathrm{P}$ from one region of a system to another, and monitoring the effects to the system voltages, V. This type of analysis is commonly referred to as a PV study.

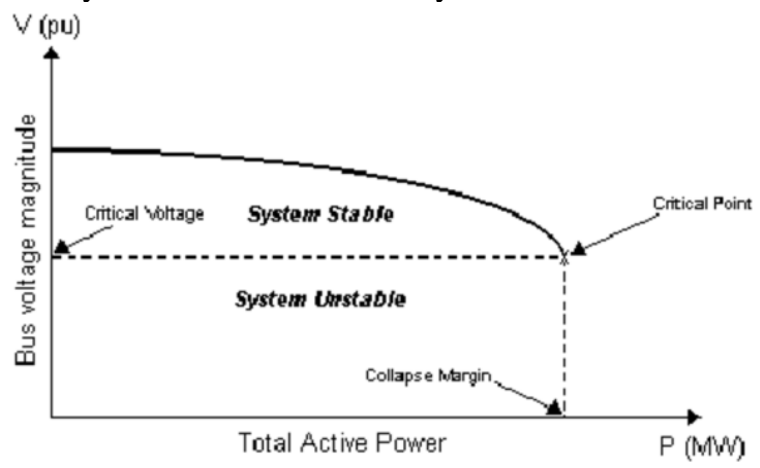

Figure. 2. Typical Power-Voltage (PV) characteristic curve

The Figure 2 shows a typical PV curve. It represents the variation in voltage at a particular bus as a function of the total active power supplied to loads or sinking areas. It can be seen that at the "knee" of the PV curve, the voltage drops rapidly when there is an increase in the load demand. Loadflow solutions do not converge beyond this point, which indicates that the system has become unstable. This point is 
called the Critical point. Hence, the curve can be used to determine the system's critical operating voltage and collapse margin. Generally, operating points above the critical point signifies a stable system. If the operating points are below the critical point, the system is diagnosed to be in an unstable condition.

\section{B. OV Curves}

Voltage stability depends on how the variations in Q and $\mathrm{P}$ affect the voltages at the load buses. The influence of reactive power characteristics of devices at the receiving end (loads or compensating devices) is more apparent in a QV relationship.It shows the sensitivity and variation of bus voltages with respect to reactive power injections or absorptions. Figure 2 shows a typical QV curve, which is usually generated by a series of load flow solutions.

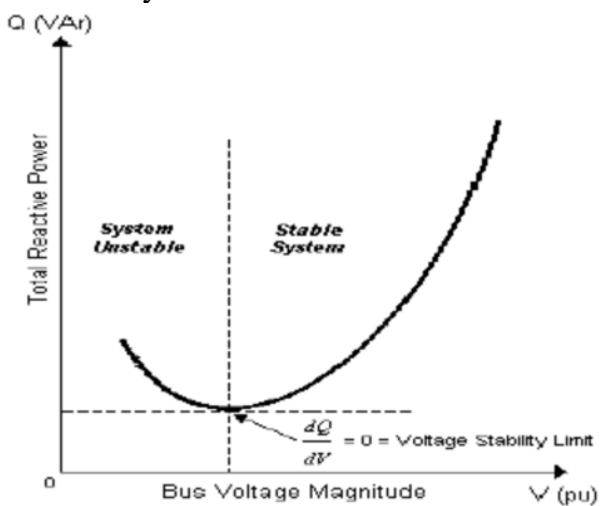

Figure.3. Typical Reactive Power-Voltage (QV) characteristic curve

Figure 3 shows a voltage stability limit at the point where the derivative $\mathrm{dQ} / \mathrm{dV}$ is zero. This point also defines the minimum reactive power requirement for a stable operation [6]. An increase in $\mathrm{Q}$ will result an increase in voltage during normal operating conditions. Hence, if the operating point is on the right side of the curve, the system is said to $\mathrm{b}$ e stable.Conversely, operating points in the left side of the graph are deemed to be unstable.

\section{RESULTS AND DISCUSSION}

\section{A. Assumptions of the Dynamic Stability Calculations}

The study cases were based on the network shown in Figures 1.The system represented for the dynamic stability simulation was a $13.8 \mathrm{kV}$ voltage source in series with an impedance. The voltage of the source was $1 \mathrm{p}$.u. The wind turbines is of $2 \mathrm{MW}$ capacity. These is represented by a single equivalent coherent fixed-speed induction generator . A lumped $11 \mathrm{kV} / 0.69 \mathrm{kV}$ wind turbine terminal transformer with 5\% impedance was used to connect the wind turbine to the $33 \mathrm{kV} / 11 \mathrm{kV}$. The computer program, PSCAD/EMTDC [7], was used to simulate dynamic stability.

\section{B. Simulation}

Many studies have been conducted on wind turbine connected to $11 \mathrm{kV}$ networks and have published several results. However, very little studies have been conducted on the reticulation regions. The 5 Bus system was adopted It was used to demonstrate the effects of wind turbine and to understand the concept of embedded generation.

The STATCOM is a two level VSC with voltage space vector PWM control. A conventional PI controller has been used to control the reactive power output of the STATCOM. For the simulation results it wased that the $11 \mathrm{kV}$ network was subjected to a single-phase fault along one of the parallel circuits, of $150 \mathrm{~ms}$ duration at 2 seconds. The faulty circuit is disconnected after the fault clearance. The main simulation results produced by using PSCAD/EMTDC are shown in Figure 4 and Figure 5.

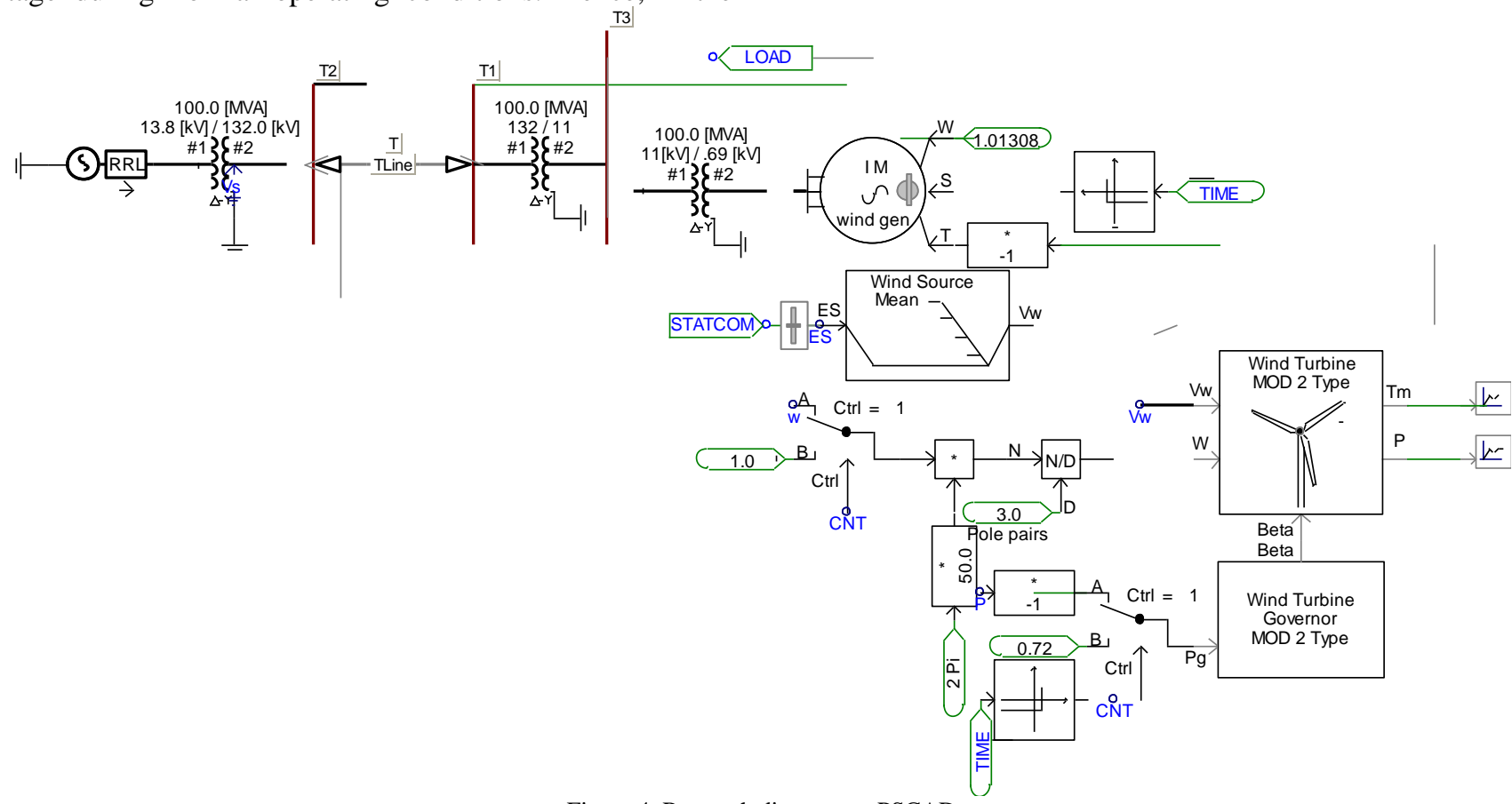

Figure 4. Research diagram on PSCAD 
The voltage response at the $11 \mathrm{kV}$ point of connection of the windfarm (busbar B4) without the STATCOM in operation is shown in Figure 5. As shown in Figure 5 the voltage at the high voltage point of connection of the windfarm (B4) does not recover the prefault voltage value after the clearance of the fault. That is, the windfarm does not have the capability to ride through the fault. However, when the STATCOM is set in operation the windfarm is able to ride through the fault.

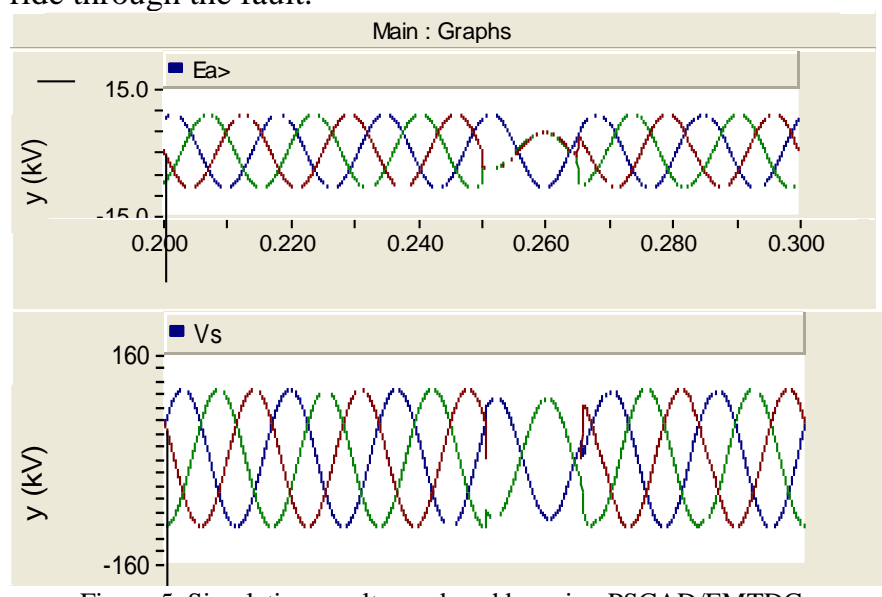

Figure 5. Simulation results produced by using PSCAD/EMTDC

The voltage recovery of the windgenerator due to the voltage support and reactive power compensation provided by the STATCOM. It can be observed that the STATCOM supplies some reactive power to the wind generator under normal operation. During the fault the reactive power supplied by the STATCOM is decreased due to the voltage drop. After the fault, the STATCOM supplies an amount of reactive power to the wind generator and compensates its requirements for reactive power in order to ride through the fault.

\section{RESULTS AND DISCUSSION}

Simulations have been performed to study the impact of network faults on the stability of small wind generators. Results are presented for single line to ground faults applied on the $11 \mathrm{kV}$ system. The most common fault is the single line to earth fault which accounts for 75-85\% of all faults [8]. The impact of 1-phase faults upon the stability of fixed speed wind farms will be much less severe.The studies indicate that faults on the distribution system (close to the windfarm) may cause instability.
The voltage drop results show that for a $100 \%$ voltage drop at the $11 \mathrm{kV}$ connection point, a very fast clearance time (less than $90 \mathrm{~ms}$ ) is required to maintain stable operation of a 2MW wind generator.Possible remedial measures are included with the use of fast acting reactive power support. The first phase of the desired work is performed and further in the second phase the Impact of FACTS on $11 \mathrm{kV}$ distribution system is studied.

\section{REFERENCES}

[1] Trinh Trong Chuong, Nguyen Van Hung, Nguyen Hoai Nam. (2019). Assessment of Wind Turbine Generators on Reliability of Distribution Network. Journal of Electrical Engineering \& Technology (2019) 14:2217-2224. https://doi.org/10.1007/s42835-019-00244-4.

[2] T. Prakash, S. Behera, M. Tripathy and J. K. Satapathy (2013). Role of STATCOM for Steady State Voltage Stability Margin Enhancement in Power Systems. 1st National Conference on Power Electronics Systems \& Applications, PESA 2013.

[3] G Elsady, Youssef Mobarak, Abdel-Raheem Youssef (2010). STATCOM for Improved Dynamic Performance of Wind Farms in Power Grid. Conference: 14th International Middle East Power Systems Conference (MEPCON), Cairo University, Egypt, pp. 471475 ,

[4] Trinh Trong Chuong. (2008). Voltage stability analysis of grids connected wind generators. The International Conference on Electrical Engineering, No. O-054.

[5] K. Pandiaraj, G. Hodgkirson, B. Fox, "Use of Embedded Generators for voltage support in rural distribution networks", UPEC $200235^{\text {th }}$ Universities Power Engineering Conference, 2000.

[6] Kundur, "Power System Stability and Control",McGraw-Hill Inc., New York, USA, 1994.

[7] PSCAD/EMTDC Simulator Version 4.2 User's Guide.

[8] European Commission Report, Integration of Renewable Resources and Distributed Generation in Energy Supply Systems, 27 September 2001 . 